\title{
Taste Coding in the Nucleus of the Solitary Tract of the Awake, Freely Licking Rat
}

\author{
Andre T. Roussin, ${ }^{1}$ Alexandra E. D’Agostino, ${ }^{1}$ Andrew M. Fooden, ${ }^{1}$ Jonathan D. Victor, ${ }^{2}$ and Patricia M. Di Lorenzo ${ }^{1}$ \\ ${ }^{1}$ Department of Psychology, Binghamton University, Binghamton, New York 13902, and ${ }^{2}$ Department of Neurology and Neuroscience, Weill Cornell \\ Medical College, New York, New York 10065
}

It is becoming increasingly clear that the brain processes sensory stimuli differently according to whether they are passively or actively acquired, and these differences can be seen early in the sensory pathway. In the nucleus of the solitary tract (NTS), the first relay in the central gustatory neuraxis, a rich variety of sensory inputs generated by active licking converge. Here, we show that taste responses in the NTS reflect these interactions. Experiments consisted of recordings of taste-related activity in the NTS of awake rats as they freely licked exemplars of the five basic taste qualities (sweet, sour, salty, bitter, umami). Nearly all taste-responsive cells were broadly tuned across taste qualities. A subset responded to taste with long latencies $(>1.0 \mathrm{~s}$ ), suggesting the activation of extraoral chemoreceptors. Analyses of the temporal characteristics of taste responses showed that spike timing conveyed significantly more information than spike count alone in almost one-half of NTS cells, as in anesthetized rats, but with less information per cell. In addition to taste-responsive cells, the NTS contains cells that synchronize with licks. Since the lick pattern per se can convey information, these cells may collaborate with taste-responsive cells to identify taste quality. Other cells become silent during licking. These latter "antilick" cells show a surge in firing rate predicting the beginning and signaling the end of a lick bout. Collectively, the data reveal a complex array of cell types in the NTS, only a portion of which include taste-responsive cells, which work together to acquire sensory information.

\section{Introduction}

Sensation is an active process, and there is increasing evidence that the purposeful acquisition of a sensory stimulus (e.g., licking, sniffing, whisking, or moving the eyes) influences neural responses at multiple levels of the nervous system (Schroeder et al., 2010). Moreover, the effects of this acquisition process are often apparent at the first synapse at which sensory signals enter the brain. For example, in the gustatory system, mechanosensory, somatosensory, and gustatory inputs generated by volitional licking of taste stimuli can interact in the nucleus of the solitary tract (NTS), the obligatory first synapse in the ascending gustatory pathway. While much is known about NTS responses in the anesthetized animal, relatively little is known about tasterelated activity in the NTS during active consumption. Given the complexity of the multimodal convergence in the NTS, it is likely that the behavior of these well described tasteresponsive cells will be significantly altered during wakefulness, or by active licking. Moreover, there may be other NTS cell types that participate in taste, but whose participation can only be appreciated during wakefulness.

Received April 17, 2012; revised June 8, 2012; accepted June 12, 2012.

Author contributions: P.M.D.L. designed research; A.T.R. and A.E.D. performed research; A.T.R., A.M.F., J.D.V., and P.M.D.L. analyzed data; A.T.R., J.D.V., and P.M.D.L. wrote the paper.

This work was supported by NIDCD Grant R01 DC006914 (P.M.D.L.). This work was done in partial fulfillment of the PhD degree for A.T.R. and for the masters degree for A.E.D.

Correspondence should be addressed to Patricia M. Di Lorenzo, Department of Psychology, Box 6000, Binghamton University, Binghamton, NY 13902-6000. E-mail: diloren@binghamton.edu.

A. T. Roussin's present address: Department of Neurobiology and Anatomy, University of Rochester, School of Medicine and Dentistry, 601 Elmwood Avenue, Box 673, Rochester, NY 14642.

DOI:10.1523/JNEUROSCI.1856-12.2012

Copyright $\odot 2012$ the authors $\quad 0270-6474 / 12 / 3210494-13 \$ 15.00 / 0$
In electrophysiological recordings from the rostral, tasteresponsive portion of the NTS in anesthetized rodents, cells with a variety of response properties have been described. These obviously include cells that respond to the various taste qualities (sweet, sour, salty, bitter, and umami), but many of these also respond to touch (Ogawa et al., 1984) and others to hot or cold (Ogawa et al., 1988). Analyses of taste coding in the NTS of anesthetized rats using the number of taste-evoked spikes as a response measure have suggested the existence of stimulus-specific cell types (for review, see Spector and Travers, 2005). However, we have shown that spike timing in taste responses can also convey a significant amount of information in the NTS (Di Lorenzo and Victor, 2003, 2007; Roussin et al., 2008; Di Lorenzo et al., 2009; Chen et al., 2011). It is unknown whether this is also the case in awake rats.

Here, we recorded from NTS cells in awake rats as they freely licked taste stimuli. Results revealed an array of cell types that reside in the taste-responsive portion of the NTS, each of which may play a role in the acquisition of information about taste. Specifically-in addition to taste-responsive cells-this region of the NTS contains cells that fire in synchrony with licks, providing a point of reference for the taste-responsive cells, and other cells that stop firing when a lick bout is initiated (i.e., "antilick" cells). Antilick cells showed a surge in firing rate before and after lick bout, providing a local representation of the behavioral and sensory mode of the rat. Among taste-responsive cells, we showed that spike timing conveys a significant amount of information about taste quality, as in anesthetized rats. In all, these data underscore the intimate association of the neural representation of taste in the NTS with behaviors related to sensory acquisition. 


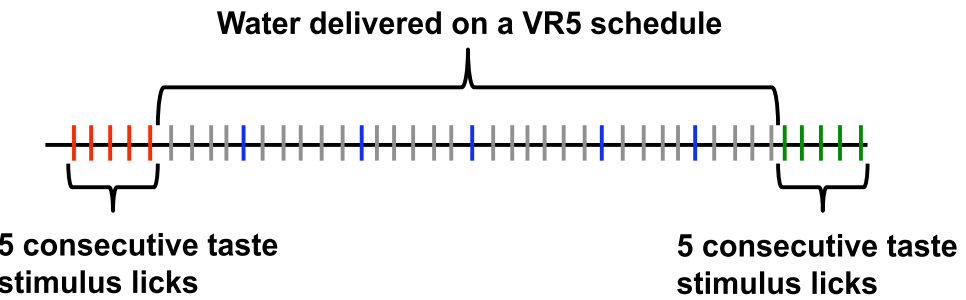

Figure 1. Diagram of the stimulus delivery paradigm. Taste stimuli are presented for five consecutive licks followed by five water rinse licks delivered on a VR5 schedule. Each lick is symbolized by a vertical line: licks that result in taste stimulus delivery are red and green; water rinse licks are blue; dry licks are in gray.

A

$$
\text { Cells tested with Low Sucrose }(\mathrm{N}=25)
$$

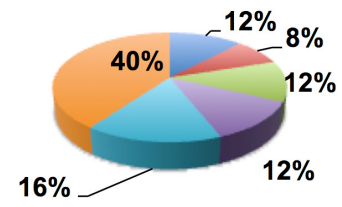

\section{No. Stimuli
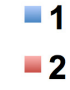

$$
=3
$$

Cells tested with High Sucrose (N=31)

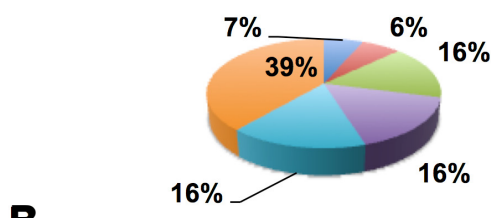

4

5

6

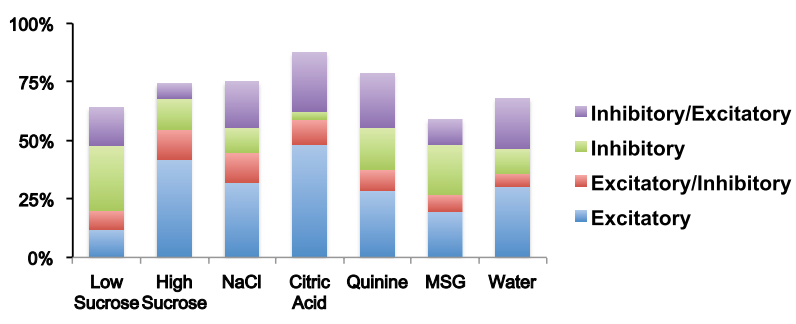

Figure 2. Taste response characteristics in the NTS of awake, freely licking rats. $\boldsymbol{A}$, The distribution of cells that respond to different numbers of taste qualities in cells tested with the low concentration of sucrose (top; $n=25$ cells in 7 rats) and those tested with the high concentration of sucrose (bottom; $n=31$ cells in 18 rats). Percentage of the total number of neurons in each category are indicated on the graph. $\boldsymbol{B}$, The distribution of the various types of responses that were recorded for each taste stimulus ( $n=56$ cells).

\section{Materials and Methods}

Subjects

Subjects were 37 male Sprague Dawley rats weighing 250-450 g. Rats were kept on a $12 \mathrm{~h}$ light/dark cycle (lights on at 7:00 A.M.) and were provided with standard rat chow ad libitum and at least $1 \mathrm{~h}$ of access to water daily. All procedures were approved by the Binghamton University Institutional Animal Care and Use Committee.

\section{Electrode implantation surgery}

Rats were anesthetized with ketamine ( $100 \mathrm{mg} / \mathrm{kg}$, i.m.) and xylazine (10 $\mathrm{mg} / \mathrm{kg}$, i.m.). The crown of the head was shaved in preparation for surgery, and the animal was mounted in a stereotaxic device with the head angled downward at $30^{\circ}$. Artificial tears were applied to the eyes to prevent drying. The top of the head was swabbed with alcohol and iodine, and an incision was made across the top of the head. The fascia was gently scraped from the top of the skull. Six stainless-steel screws were implanted in the top of the skull to anchor the head cap. A small hole was drilled $1.8 \mathrm{~mm}$ lateral to lambda and $15.3 \mathrm{~mm}$ posterior to bregma. The underlying dura was punctured and moved aside. In some animals, a probe electrode (insulated tungsten, $20 \mathrm{M} \Omega$; FHC) was lowered into the brain at the coordinates described above for an initial exploratory track, and extracellular activity was recorded. Once the electrode tip had passed below the cerebellum (usually $3-4 \mathrm{~mm}$ ), the tongue was periodically bathed with a solution of $0.1 \mathrm{M}$ $\mathrm{NaCl}$, followed by a distilled water rinse, to test for taste responses. The electrode was lowered $5-6 \mathrm{~mm}$ or until a taste response was observed.

Microwire assembly electrodes (described below) were implanted chronically. If an exploratory track had been made, implantation coordinates were $100 \mu \mathrm{m}$ dorsal to the previously identified taste-responsive region of the NTS because upward movement of the brain often occurs after surgery. If no exploratory track was made, the electrode bundle was lowered to $5.5 \mathrm{~mm}$ below the cerebellar surface. In either case, the microwire assembly was then cemented to the head with dental acrylic.

Electrodes consisted of a bundle of eight microwires $(25-\mu \mathrm{m}$-diameter tungsten insulated with Formvar; California Fine Wire). One end of each microwire was soldered to a head cap (CON/8o50m-10P; Plexon). A bare tungsten strut ( $10 \mathrm{~mm}$ long; 0.005 inch diameter; FHC) was soldered to the ground pin on the head cap. The free ends of the microwires were gathered into a bundle, sterilized, and cemented to the tungsten strut (also sterilized) at the base of the head cap with liquid plastic insulation. The microwires were cut so that the ends of the wires were staggered over $\sim 1 \mathrm{~mm}$ and extended $\sim 1-2 \mathrm{~mm}$ below the end of the tungsten strut. The bundle of microwires was adhered to the tungsten strut by dipping it into a warmed, liquefied sucrose-gelatin mixture and allowed to dry. The design of the electrodes allowed the microwires to migrate from the tungsten strut as the gelatin dissolved with body heat. This was confirmed from histological data. It normally took at least a week following electrode implantation surgery (including $5 \mathrm{~d}$ of postoperative recovery) for single cells to appear in the recordings. We assume, therefore, that tissue adherence to the microwires fixed the tips to some extent, enabling recordings that were generally stable throughout an experimental session. For most rats with successful implantations, we were able to obtain single-cell or multicell recordings for $\sim 2$ weeks; we presume that scar tissue made recordings impossible beyond this point. Our yield of rats with successful recordings was approximately one in four.

Animals were given buprenorphine $\mathrm{HCl}(0.4 \mathrm{mg}$, s.c.) and gentamicin ( $0.4 \mathrm{mg}$, s.c.) immediately following surgery and once daily for $3 \mathrm{~d}$ thereafter. Topical antibiotic was administered around the head cap as well. Body weight and general well-being were monitored after surgery. Testing began $6 \mathrm{~d}$ after surgery.

\section{Testing chamber}

Electrophysiological recordings took place in a MED Associates operant chamber housed within a sound-attenuating box. Taste stimuli were delivered via a sipper tube in a licking recess at one end of the chamber. This sipper tube consisted of an array of 1220 gauge stainless-steel tubes housed within a larger stainless-steel tube $8 \mathrm{~mm}$ in diameter. The ends of the smaller tubes were flush with the end of the larger tube. Taste solutions were held under $\sim 10 \mathrm{psi}$ of compressed air and delivered to the lick spout through polyethylene tubing. Stimulus delivery was controlled by solenoids (Parker Hannifin) that delivered $12 \mu \mathrm{l}$ of fluid within $10 \mathrm{~ms}$ after the rat broke an infrared beam close to the sipper tube in the licking recess. The stimulus delivery system was calibrated daily before the rats were tested.

\section{Taste stimuli}

Taste stimuli included aqueous solutions of $\mathrm{NaCl}(0.1 \mathrm{M})$, sucrose (low, $0.05 \mathrm{M}$; high, $0.1 \mathrm{M})$, citric acid $(0.01 \mathrm{M})$, quinine $\mathrm{HCl}(0.0001 \mathrm{M})$, monosodium glutamate (MSG) $(0.1 \mathrm{M})$, and distilled water. These concentrations are comparable with those used by Stapleton et al. (2006) in their study of cortical taste responses. For sucrose, 58 cells (of which 25 were taste-responsive) were tested using $0.05 \mathrm{M}$ and 49 cells (of which 31 were taste-responsive) were tested with $0.1 \mathrm{M}$. All taste stimuli were reagent grade, mixed with distilled water, and presented at room temperature. In 
general, results obtained from cells tested with the two different sucrose levels were similar, and, except where noted, we combine these subsets.

\section{Recording}

Neural activity was monitored continuously throughout experimental sessions using a speaker and oscilloscope, and recorded using SortClient software (Plexon). Waveforms were sorted off-line using template matching and principal components analysis with Off-line Sorter software (Plexon). Criteria for isolation included a signal/noise ratio of $\geq 3: 1$ and a refractory period of at least $2 \mathrm{~ms}$ (Stapleton et al., 2006). The time stamps and waveforms of individual spikes were saved to a file $(25 \mu \mathrm{s}$ resolution), along with the precise timing of licks and stimulus deliveries (25 $\mu$ s resolution).

\section{Behavioral testing}

Following recovery from surgery, rats were habituated to the testing chamber and trained to drink distilled water from the drinking spout before testing to ensure stable licking patterns. Water bottles were removed from home cages $18-24 \mathrm{~h}$ before the beginning of every recording session. For recording sessions, a head stage was affixed to the animal's head cap, and the animal was placed into the recording chamber immediately before a recording session. A cable attached to the head cap tethered the rat to the recording apparatus. Animals were free to move about the chamber. The house light within the recording chamber turned on when the session began and turned off when taste stimuli were no longer available. Stimulus delivery was controlled using MedPC software (MED Associates). Testing sessions lasted 30 min. Thirty minutes after the session ended, rats were given $1 \mathrm{~h}$ ad libitum access to water in their home cages.

\section{Stimulus delivery and reinforcement paradigms}

The paradigm for stimulus delivery and reinforcement contingencies was as follows: Each tastant was presented for five consecutive licks followed by a variable ratio (VR) schedule in which five water "rinse" licks were presented, interspersed among four to six "dry" licks where no fluid was presented (thus, it was called a VR5). These dry licks both followed and preceded the "reinforced" lick. Figure 1 illustrates the sequence of reinforced and dry licks in a session. Each reinforced lick produced $\sim 12 \mu \mathrm{l}$ of fluid. This paradigm presented tastants in a way that was similar to the way that an animal would normally lick a tastant (i.e., consecutive licks). The use of the VR schedule for water rinses served two purposes: First, it ensured that the rat would not satiate too quickly, and second, it provided a control for purely motor and somatosensoryevoked responses.

\section{Data analysis}

General. Spontaneous firing rate was calculated from a $10 \mathrm{~s}$ sample of the experimental session in which no licking occurred.

A taste response was identified as a significant change in firing rate compared with baseline. Baseline was defined as the $0.5 \mathrm{~s}$ of neural activity just before the initial stimulus lick of a trial of five consecutive stimulus licks, calculated as spikes per second (sps) across all stimulus trials. This period generally included only dry licks (no water licks), since rats lick at $\sim 6-8$ licks/s. The baseline was divided into $100 \mathrm{~ms}$ bins, and the mean and SD were calculated. Following the initial stimulus lick of a trial, a sliding window of $100 \mathrm{~ms}$ length was moved in 20 $\mathrm{ms}$ increments until the firing rate (in spikes per second) was at least 2.58 SD (99\% significant) either above (excitatory) or below (inhibitory) the average baseline firing rate. The trailing edge of the first significant bin of
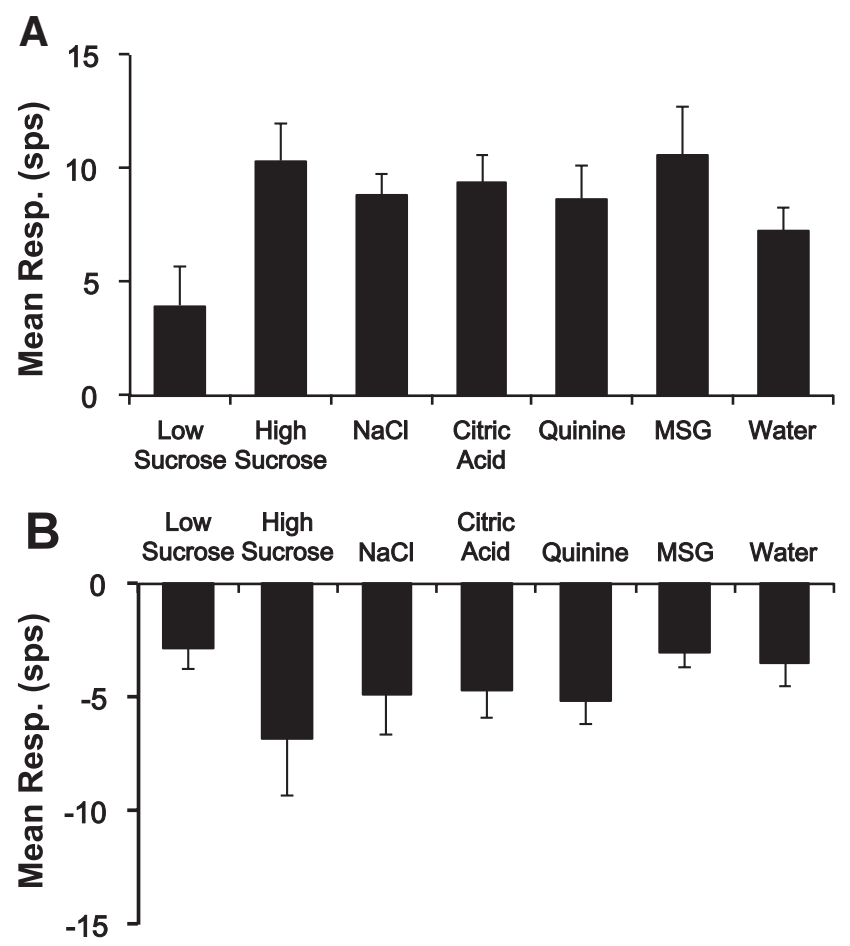

Figure 3. Mean response magnitudes in spikes per second \pm SEM across taste-responsivecells in the NTS in awake, freely licking rats. Baseline firing rates are subtracted from taste-evoked firing rates. $\boldsymbol{A}$, Excitatory responses ( $n=198$ total). $\boldsymbol{B}$, Inhibitory responses ( $n=140$ total).

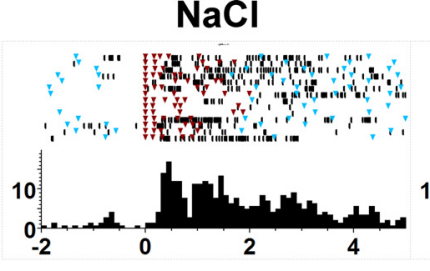

Quinine
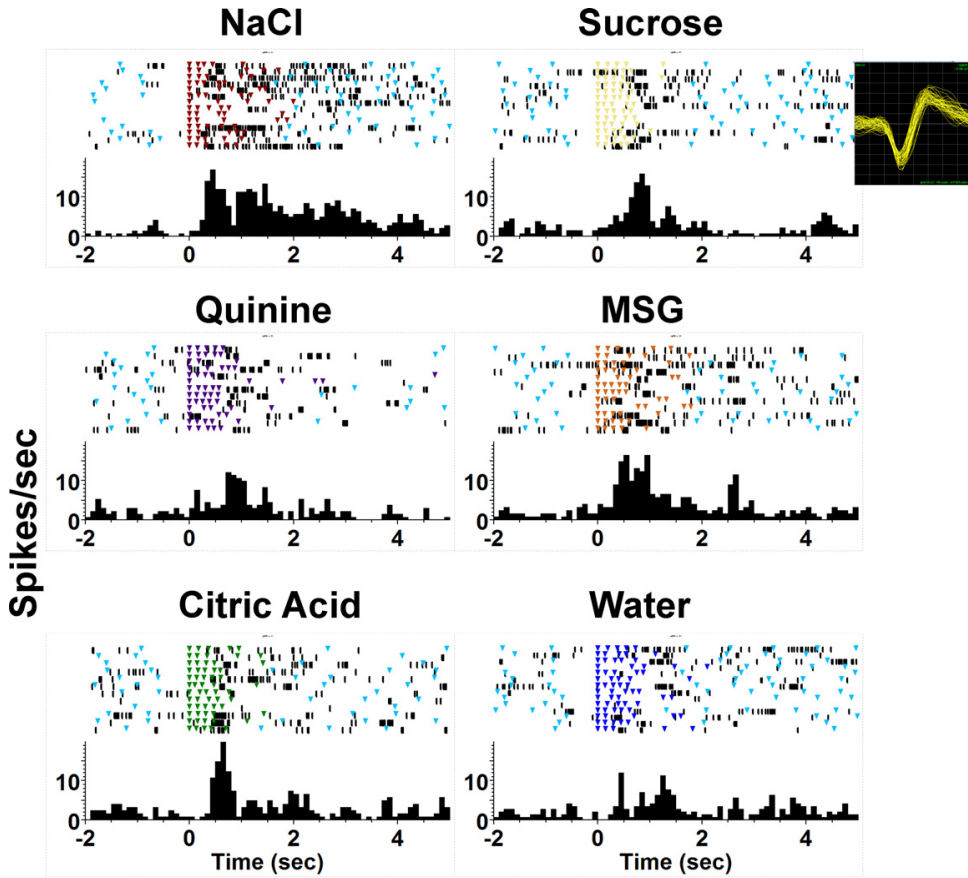

Figure 4. Example of a broadly tuned taste-responsive NTS cell. The top of each panel shows a raster of taste-evoked spike activity; each dot indicates the occurrence of a spike; each colored dot indicates the delivery of a fluid with a lick; the light blue dots indicate the delivery of water with a lick. Dry licks that occur between water deliveries following stimulus trials are not shown. The bottom of each panel shows PSTHs of taste responses. Time bin, $100 \mathrm{~ms}$. The inset at the top right shows the waveform of the cell. the response was defined as the response latency. The $100 \mathrm{~ms}$ time bin was then stepped in $20 \mathrm{~ms}$ increments until the firing rate in that bin was no longer significantly different from baseline. This procedure tolerated a single nonsignificant step if and only if the succeeding step showed a significant difference from baseline. Otherwise, the leading edge of the 
last significant $100 \mathrm{~ms}$ bin was considered the end of the response. For inhibitory responses, if baseline minus $2.58 \mathrm{SD}$ fell below zero, a fall in firing rate to zero was considered as a significant response if the baseline firing rate was at least 2.0 sps.

On average, cells were recorded from $1.5 \pm 0.2$ (SEM) electrodes/rat (median, 1 ; range, $1-5$ ); $1.6 \pm 0.2$ cells were recorded per electrode (median, 1 ; range, 1-6). It should be noted that some electrodes yielded recordings of single cells on different days. The number of electrodes yielding recordings on $1,2,3,4,5$, and $6 \mathrm{~d}$ were $48,8,6,1,3$, and 1 , respectively. In cases in which cells were recorded from the same wire on different days, we considered these recordings to represent different cells. These recordings on different days showed distinct patterns of taste responsiveness. Given the small size of the cells in the taste-responsive portion of the NTS (Schweitzer et al., 1995) and the fact that these cells are notoriously difficult to isolate even in the anesthetized preparation, we felt it was unlikely that a cell could be held for $>24 \mathrm{~h}$. However, we cannot unequivocally rule out the possibility that the same cell was present for multiple days on the same wire. Since animals generally experienced several days of recording before an isolatable cell appearing in the record, they already had had a good deal of experience with all taste stimuli. Thus, changes in taste responsiveness were presumably not due to changes in familiarity.

Analyses of temporal coding in responses from single cells. The information content of taste responses was analyzed as previously described (Di Lorenzo and Victor, 2003), using metric space analyses (for further details, see Victor and Purpura, 1996, 1997). This analysis quantified the amount of information about taste quality contributed by firing rate alone, by the change in firing rate over the time course of a response, and by spike timing. The key quantity is the "distance" between two spike trains, which is quantified as the minimum cost of inserting, deleting, or moving spikes in one train, to make one spike train match the other. The cost of inserting or deleting a spike from a spike train is always set at 1 . The cost of moving a spike (per unit time) is $q$, which is varied parametrically to examine responses at multiple levels of temporal precision. The distance between two spike trains in terms of spike count alone is the cost obtained when $q=0$ (because there is no cost associated with moving a spike); this is simply the difference between the spike count of each response and is called $D^{\text {count }}$. To take into account the temporal characteristics of the spike trains, we calculate the distance for a range of values $q>0$, denoted $D^{\text {spike }}[q]$. The parameter $q$ (in units of $1 /$ second) determines the temporal precision of the analysis, since the cost of moving a spike by an amount $1 / q$ is equal to the cost of deleting it altogether. Calculations were performed for $q=0$, and in half-octave steps from $q=0.0625 / \mathrm{s}$ to $512 / \mathrm{s}$.

To estimate the amount of information conveyed by spike timing for each cell, we determined the extent to which pairs of responses to the same stimulus tended to be closer to each other than pairs of responses to different stimuli, using $D^{\text {spike }}[q]$ as a measure of proximity. A spike train $S$ was classified as belonging to the response class corresponding to the stimulus $R$ if the average distance $D^{\text {spike }}[q]$ from $S$ to each of the spike trains elicited by the stimulus $R$ was shorter than the average distance from $S$ to the responses elicited by any other stimulus. As in previous work, average distances were calculated after an inverse-square transformation, to emphasize near matches over mismatches. We then calculated information, $H$, from the confusion matrix between the actual stimulus that elicited each response, and the response class to which it was assigned by this proximity rule. The value of the information, $H$, thus indicates the performance of stimulus-dependent clustering based on the temporal patterns of taste responses (i.e., how well the taste responses can be decoded). Animals in our experiment were presented with six stimuli [five aqueous solutions (see above) and water]; the amount of information required for perfect discrimination among six stimuli is 2.58 bits. If the classification is totally random, $H=0$.

The value of information for $q=0$ is denoted as $H_{0}$ and indicates information conveyed by spike count alone (i.e., a rate code). The value of $q$ at which $H$ is greatest is referred to as $q_{\max }$ and the maximal value of $H$ (i.e., its value at $\left.q_{\max }\right)$ is $H_{\max }$. When $H_{\max }$ was greater than the value of $H$ at $q=O\left(H_{\text {count }}\right)$, the time course of the response and/or the timing

\section{$\triangle \Delta \cdot$ Low Sucrose}

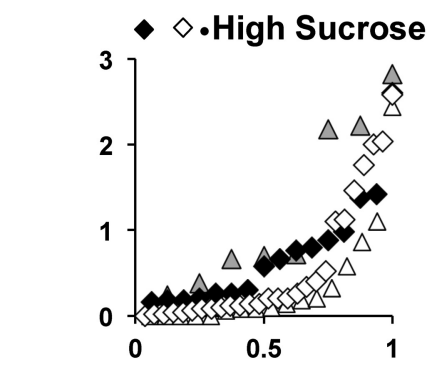

$\diamond$.Excitatory $\diamond$.Inhibitory
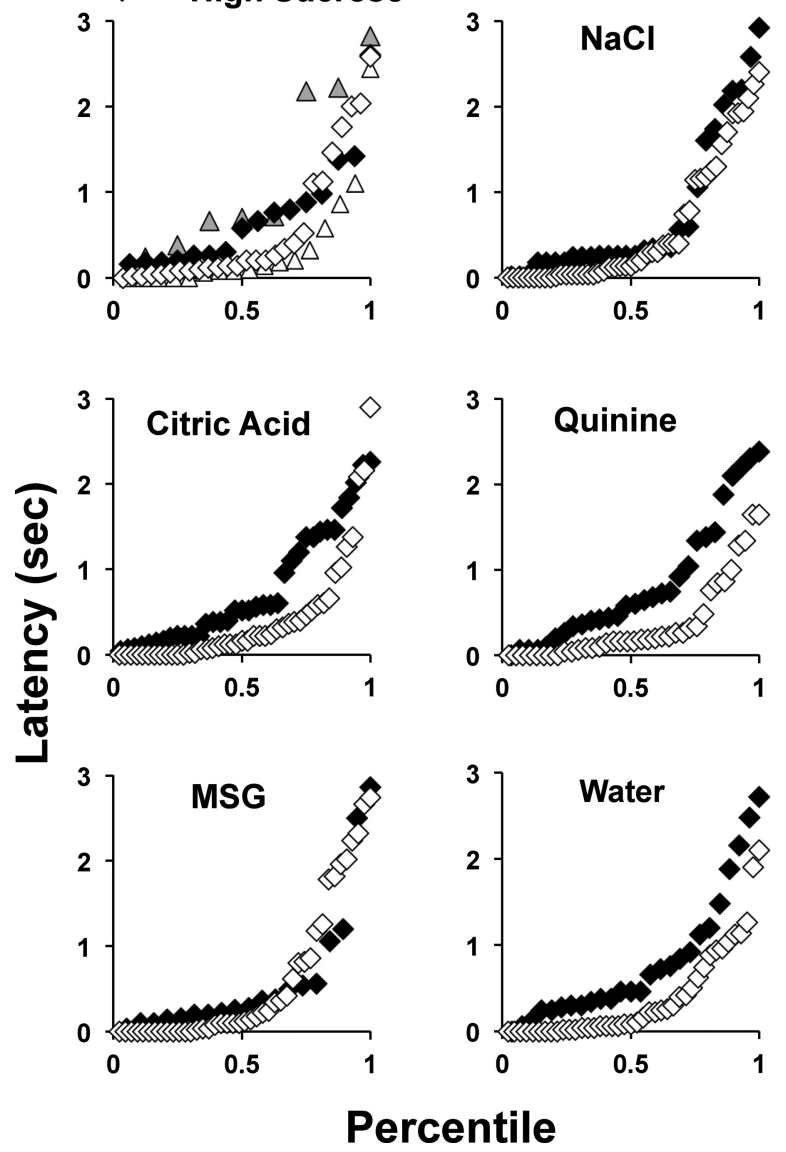

Figure 5. Cumulative distribution of latencies of excitatory (filled symbols) and inhibitory (open symbols) taste responses for all taste stimuli plus water, as a fraction of the total. The numbers of excitatory responses are as follows: low sucrose, 9; high sucrose, 19; $\mathrm{NaCl}, 36$; citric acid, 47; quinine, 34; MSG, 21; water, 32. The numbers of inhibitory responses are as follows: low sucrose, 13; high sucrose, 10; $\mathrm{NaCl}$, 24; citric acid, 22; quinine, 28; MSG, 22; water, 21.

of individual spikes contributed information above that contained in the spike count.

Two control analyses were performed (Di Lorenzo and Victor, 2003, 2007). First, to account for a possible upward bias in $H$, the metric space analysis was repeated for 40 surrogate data sets in which the stimuli associated with the spike trains were randomly shuffled. Taste responses were considered significant only if $H_{\max }$ was at least 2 SDs greater than the average amount of information in the shuffled datasets $\left(H_{\text {shuffled }}\right)$ at $q_{\max }$. Second, to determine whether the information contained in the temporal structure of the spike trains could be accounted for by the rate envelope, $H_{\max }$ was compared with values obtained from another group 10 of surrogate data sets $\left(H_{\text {exchange }}\right)$. The surrogates were created by randomly exchanging individual spikes between two responses to the same stimulus (while preserving their occurrence times). Thus, this surrogate dataset retained the average firing rate of the original data for each stimulus, but detailed firing patterns were destroyed by the shuffling process. If $H_{\max }$ (calculated from the original data) was greater than $H_{\text {exchange }}+2 \mathrm{SD}$ (calculated from the surrogates), we concluded that contribution of spike timing was greater than what could be accounted for by the rate envelope. For the cells in which the above estimates of $H_{0}$ and $H_{\max }$ were significantly greater than 0 (i.e., greater than $H_{\text {shuffled }}+2 \mathrm{SD}$ ), we corrected their values for the bias due to the limited number of samples by the TPMC (Treves-Panzeri-Miller-Carlton) debiaser (Miller, 1955; Carlton, 1969; Treves and Panzeri, 1995). For cells in which the above estimates of $H_{0}$ and $H_{\max }$ were not significant (i.e., less than $H_{\text {shuffled }}+2 \mathrm{SD}$ ), we took the final values of $H_{0}$ and $H_{\max }$ to be zero. In general, the debiased estimate was 
only $>0$ when the uncorrected information estimate was greater than the $H_{\text {shuffled }}+2 \mathrm{SD}$.

The above calculations were performed using the Spike Train Analysis Toolkit (Goldberg et al., 2009) and in-house MATLAB software.

\section{Histology}

To reconstruct the electrode placements, rats were given a lethal dose of sodium pentobarbital. A lesion was created at the tip of the recording electrode(s) where taste responses were recorded. The rats were then perfused transcardially with isotonic saline $(0.15 \mathrm{M} \mathrm{NaCl})$ and formol saline (10\% formaldehyde in 0.15 $\mathrm{M} \mathrm{NaCl}$ ). Brains were removed and stored in formol saline for 1 week. Frozen sections (40 $\mu \mathrm{m}$ thick) were cut through the NTS on a cryostat, mounted on gelatinized slides, and stained with cresyl violet.

\section{Results}

General response characteristics of taste-responsive cells

Electrophysiological records were obtained from 107 cells in 37 rats, with each taste stimulus presented for between 2 and 32 trials (median, 10 trials). Fifty-six of these cells ( $52 \%$ ) had a taste response to at least one of the five chemical stimuli, or to water, and were therefore considered taste responsive. Since a large proportion of these cells (Fig. 2A) responded to all five taste stimuli and also to water, we analyzed all six stimuli on equal footing below. Among the 56 taste-responsive cells, there were 14 cells (25\%) that also showed strong lick-related activity. An additional 23 cells showed lick-related activity without differential responses to taste stimuli. Finally, there were 28 cells that became silent when the animal licked. We called these antilick cells and describe them in detail below.

Figure $2 B$ characterizes the overall characteristics of the population in terms of the excitatory versus inhibitory nature of the response. Excitatory, inhibitory, and mixed excitatory/inhibitory responses were all apparent in NTS cells, and, to varying degrees, for all six taste stimuli. In some cells, excitation preceded inhibition and in others the reverse was true. Analyses of response magnitudes showed that the high concentration of sucrose evoked the largest firing rate for excitatory responses and the largest decrease in firing rate for inhibitory responses (Fig. 3). For excitatory responses, the order of effectiveness was high sucrose $>$ MSG $>$ citric acid $>$ $\mathrm{NaCl}>$ quinine $>$ water $>$ low sucrose; for inhibitory responses, in terms of the size of the decrement with respect to baseline firing rates, high sucrose $>$ quinine $>\mathrm{NaCl}>$ citric acid $>$ MSG $>$ water $>$ low sucrose.

Figure 4 shows an example of the responses to taste stimuli in a typical multisensitive cell. In this figure, raster plots are shown above the peristimulus time histogram (PSTH) for each stimulus. Each colored dot in the raster plots represents a lick that produced some fluid; dry licks are not shown. It can be seen that this cell responded
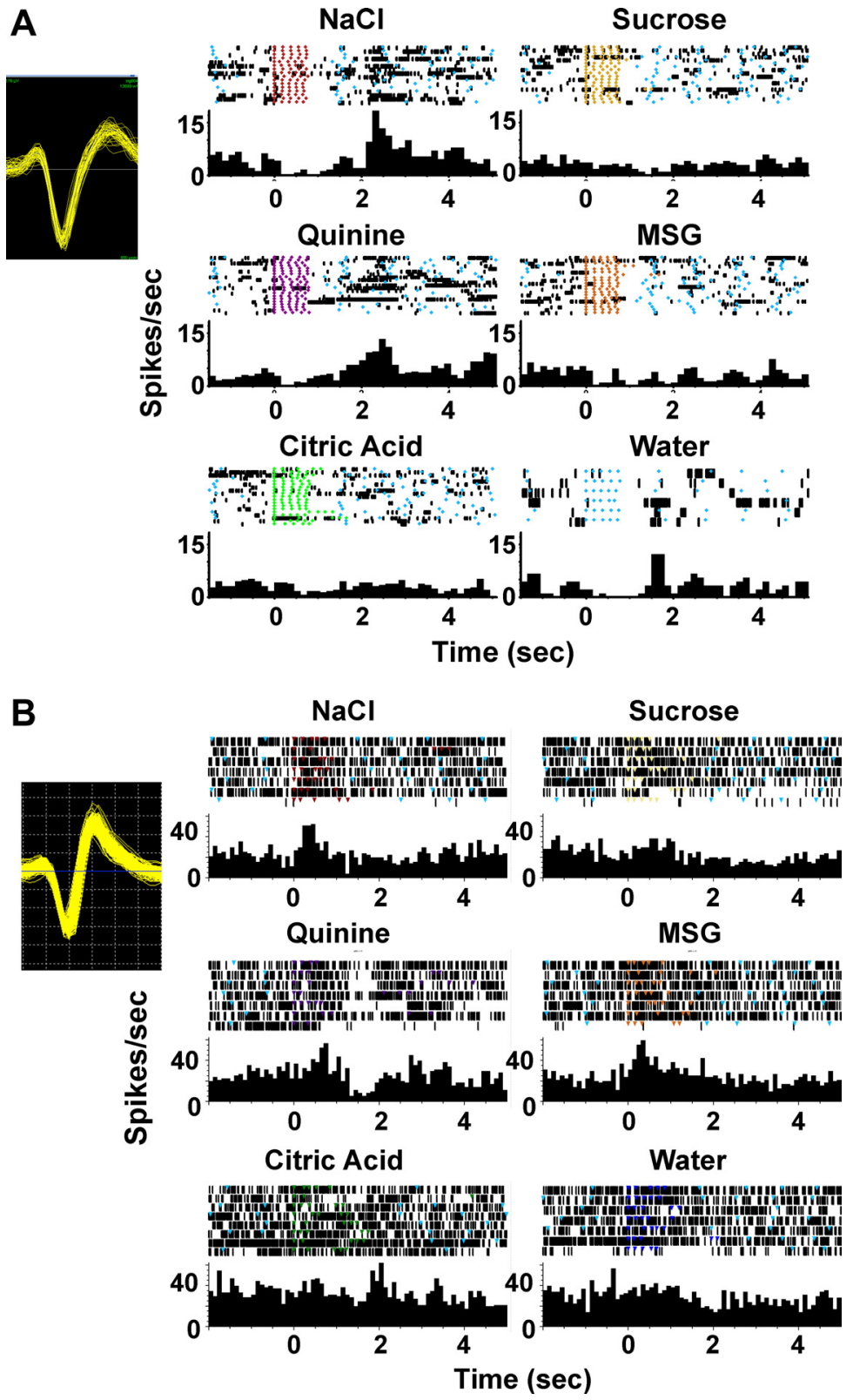

Figure 6. $\quad \boldsymbol{A}$, Example of taste responses in an NTS cell with a long-latency response to $\mathrm{NaCl}$ and quinine. There were 24 cells that showed such responses. $\boldsymbol{B}$, Example of taste responses in an NTS cell with short-latency excitatory responses to $\mathrm{NaCl}$ and MSG, and a long-latency inhibitory response to quinine. There were 14 cells recorded from 12 rats that showed both short- and long-latency responses. Rasters and PSTHs are as in Figure 4. The insets at top left show the waveform of the cell.

best to $\mathrm{NaCl}$ but responded to the other tastants as well. There was a modest but definite response to water in this cell.

Latencies of taste responses varied widely, both across cells and among the responses of a single cell to different stimuli. Figure 5 shows the cumulative distribution of latencies of excitatory and inhibitory responses across cells. This figure demonstrates that, in many cells, taste responses did not even begin until after the stimulus lick sequence was completedthis occurs within $1 \mathrm{~s}$, given an average lick rate of $6-8 / \mathrm{s}$. These long-latency responses (i.e., responses with a latency $\geq 1$ s) were elicited by all tastants, in at least a fraction of the cells. Across the population, long-latency excitatory responses were seen in 24 NTS cells (of 56; 43\%); long-latency inhibitory responses were seen in 15 (of 56;27\%). Both long and short latencies to different tastants in the same cell were observed in 

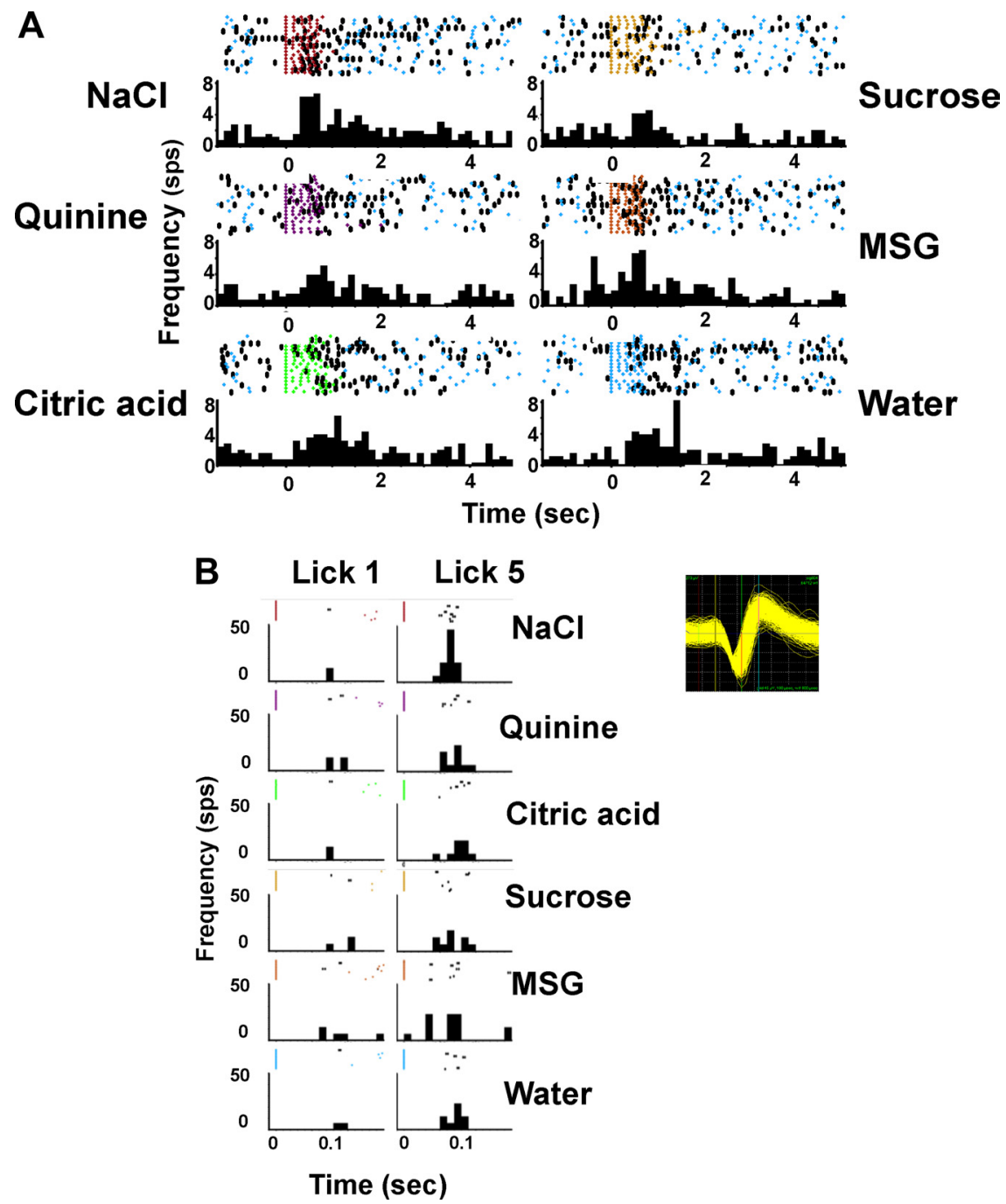

Figure 7. Taste-evoked responses in an NTS cell that showed prominent lick-related activity. There were 14 such cells. Rasters and PSTHs are as in Figure 4. The inset at bottom right shows the waveform of the cell. $\boldsymbol{A}$, Responses are shown to all taste stimuli plus water for $5 \mathrm{~s}$ after the initial stimulus lick. $\boldsymbol{B}$, Responses to all stimulus licks are shown at an expanded timescale (time bin, 10 ms) to illustrate lick-related activity. Note that this is selective for specific stimuli: it is prominent for $\mathrm{NaCl}$, but for citric acid, it is no larger than the response to a dry lick (final panel).

11 cells. Figure $6 \mathrm{~A}$ shows an example of a cell with longlatency excitatory responses to $\mathrm{NaCl}$ and quinine; Figure $6 B$ shows an example of a cell with short-latency excitatory responses to $\mathrm{NaCl}$ and MSG and a long-latency inhibitory response to quinine.

A more detailed analysis of latency provides an indication of how sensory and motor signals interact. As we defined it here, the latency is the time between the first presentation of the stimulus and the first reliable change of the neural response. This latency, which determines the earliest time at which the neuron can provide information about the tastant, is clearly relevant to behavior. But it is also a measure that is affected by the consequences of motor acts, since the stimulus enters the mouth lick by lick (as in the natural setting). To highlight this interaction, we can instead focus on the time difference between the lick itself and the neural response, comparing each period of postlick activity to the comparable period that follows a dry lick [as did Stapleton et al. (2006, 2007)]. This can yield a very different value, as shown by the example in Figure 7. This cell showed excitatory responses to all tastants (including water) except citric acid (Fig. 7A), all at rela- tively short latencies (the response to $\mathrm{NaCl}$ shown in Fig. 7A, for example, had a latency of $220 \mathrm{~ms}$ ). Figure $7 B$ plots the responses of the same cell, showing the responses on a finer timescale, with the responses to each individual lick aligned to the lick time. It can be seen that all licks, including dry licks in which no fluid is delivered, evoked a burst of spikes; however, there was a clear difference in the intensity of the lick-evoked responses according to the particular stimulus. This activity occurred within $\sim 30 \mathrm{~ms}$ of the preceding lick. The reason that the response latency (with respect to initial stimulus delivery) was much longer is that the responses to individual licks build up slowly over time, and do not exceed threshold until multiple licks have occurred. Note, however, that this buildup is selective and, thus, does not simply reflect an increase in neural activity due to activity associated with licking: citric acid, which does not evoke an evident response at the finer timescale (Fig. 7B), also does not evoke a response that builds over time (Fig. 7A). This buildup in time is also demonstrated by the example neuron of Figure 8 , in which we were able to record a sufficient number of spikes to delineate the response to each lick. In Figure $8 \mathrm{~A}$, the responses over the complete five lick trial are shown, demonstrating responses to $\mathrm{NaCl}$, citric acid, quinine, and water at latencies ranging from 100 to $460 \mathrm{~ms}$. Responses to the first and fifth licks of each tastant are shown in Figure 8B. Although there was no response at all to the first lick, by the fifth lick, stimulus-specific responses were apparent-and, as in the overall responses of Figure $8 \mathrm{~A}$, the largest of these is to $\mathrm{NaCl}$. Finally, we note that, in the present paradigm, each reinforced lick produced $\sim 12 \mu \mathrm{l}$ of fluid, an amount that is more than twice what a rat would acquire with a "normal" lick (i.e., $\sim 5 \mu \mathrm{l}$ ). It is possible, then, that in nature, the ramp-up of neurophysiological responses occurs even more slowly, as fluid accumulates in the mouth over 10 or more licks.

Temporal coding of information about taste quality

Metric space analyses were applied to taste responses in cells with at least six trials of each of the five basic tastes and water. Forty cells satisfied these criteria, 22 cells that were tested with the low concentration of sucrose and 18 that were tested with the high concentration of sucrose. Responses were analyzed over several intervals from stimulus onset: $200 \mathrm{~ms}, 500 \mathrm{~ms}, 1.0 \mathrm{~s}, 1.5 \mathrm{~s}$, and $2 \mathrm{~s}$. At each time point, the average amount of information per cell was computed from the debiased estimates of $H_{\max }$, along with the number of cells for which the amount of information was significantly greater than 0 (see Materials and Methods). Corresponding values for $H_{\text {count }}$ are also shown. In addition, the amount of information about taste quality carried by the licks was evaluated similarly. To do this, the occurrence of a lick was 
treated as if it were a spike, and the information conveyed by the licks [taking into account the number of licks and their temporal pattern (i.e., $\left.\left.H_{\max }\right)\right]$ was calculated with metric space analyses. These analyses allowed us to address two issues: first, whether the information conveyed by the neural activity merely reflected information contained within the lick pattern, and second, how the information carried by the neural activity evolved over time.

With regard to the first question, whether the information contained in the neural activity could have been derived just from the licks, the results in Figure 9 showed that this could not be the case. Specifically, at all times except the last, the responses of individual neurons, on average, contained more information $\left(H_{\max }\right.$ for cells; red trace) than the licks (green trace). To make this observation more precise, we compared the information contained in each neural response for which $H_{\max }>0$ with the information contained in the licks recorded at the same time. The information in the spiking responses was larger than the simultaneously recorded lick responses, at all time points except the last $(p<0.01$ at 200 , $500,1000,1500 \mathrm{~ms}$ ). This indicates that the information conveyed by the units could not have been derived from the lick sequence-since, according to the dataprocessing inequality (Cover and Thomas, 1991), processing a signal cannot increase the amount of information it contains. At the final time point (2000 $\mathrm{ms})$, the average amount of information carried by the licks exceeded the amount of information carried by the typical neuron (Fig. 9). However, at this time point, the stimulus is no longer present in the mouth, so the functional relevance of a comparison at this time point is unclear.

With regard to the question of how the representation of taste information carried by neural responses evolves over time, Figure 9 shows that temporal coding plays an increasing role as time progresses. This is shown two ways. First, the difference between the amount of information conveyed by the temporal characteristics of the taste-evoked spike train and that conveyed by spike count alone increases as the response is elaborated over time. Second, the number of cells that contributed a significant amount of information through the temporal characteristics of their responses also grew as the response interval lengthened. Thus, information about a taste stimulus is conveyed by both the temporal characteristics of the spike train as well as the spike count, with the temporal characteristics becoming more important as the response progresses. Interestingly, the level of temporal precision at which information is maximized, $q_{\max }$, is high when measured over short response intervals but becomes increasingly coarse at longer response intervals, suggesting that the temporal precision of the initial spikes at which information is conveyed is greater than that of the later ones.
To further analyze the nature of temporal coding in NTS neurons, we performed the surrogate analysis described in Materials and Methods. We focused this analysis on those neurons for which temporal coding was present (i.e., the neurons with $q_{\max }>$ 0 , and $H_{\max }>H_{\text {count }}+2 \mathrm{SD}$ ). We then asked whether the contribution of temporal coding could be accounted for by modulation of the firing rate envelope. To do this, we compared the amount of information in the actual response with the amount of information in artificial responses synthesized to have the same firing rate envelope, but with spike times exchanged between trials so that any possible firing patterns were eliminated. Cells for which the original data had a greater amount of information than the exchange-resampled surrogates $\left(H_{\max }\right.$ $\left.>H_{\text {exchange }}+2 \mathrm{SD}\right)$ were then considered to demonstrate temporal coding via spike timing, and not just as a consequence of the firing rate envelope.

Figure 10 summarizes the analysis. This figure shows a direct comparison of the contribution of spike count to the maximum amount of information for each cell. Data are taken for the first $2.0 \mathrm{~s}$ of the stimulus trial. Symbols that are placed above the diagonal are those for which the temporal characteristics of the response contribute more information than spike count alone (i.e., $H_{\max }>H_{\text {count }}$ ). The gray squares indicate those cells that convey information 


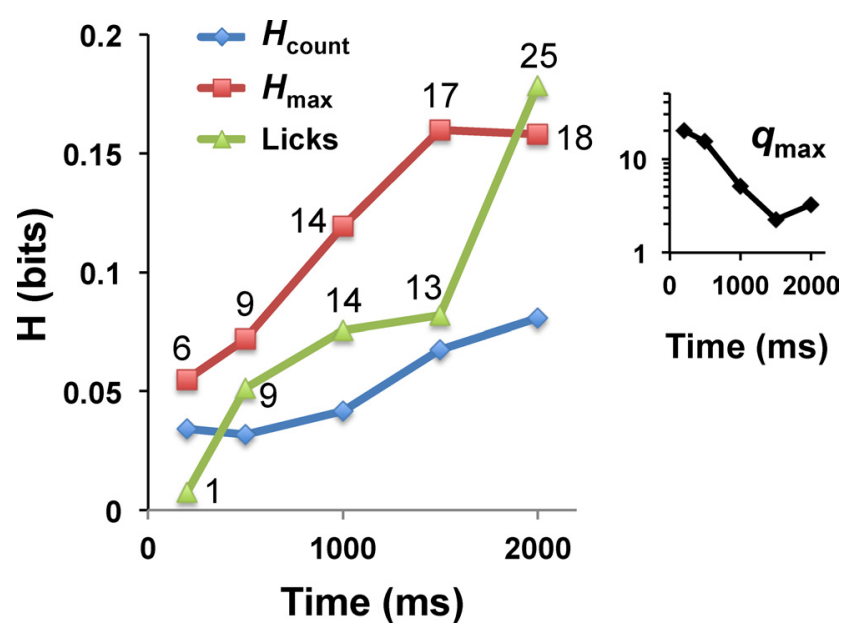

Figure 9. Summary of results of metric space analyses of taste responses in NTS cells for response intervals following the first stimulus lick of the five lick sequence. Response intervals of $100 \mathrm{~ms}, 200 \mathrm{~ms}, 500 \mathrm{~ms}, 1.0 \mathrm{~s}, 1.5 \mathrm{~s}$, and $2.0 \mathrm{~s}$ of activity were analyzed. Values plotted for $H_{\text {count }}$ and $H_{\text {max }}$ are the average amount of information per cell (in bits), across the population of 40 taste-responsive cells in which at least six presentations of each stimulus were recorded. $H_{\text {count }}$ considers information carried by spike count and $H_{\text {max }}$ takes into account the temporal pattern of the response as well. The number next to each point is the number of cells for which the information estimate was significantly greater than 0 . The trace labeled "lick" is the corresponding estimate of information $\left(H_{\max }\right)$ contained in the temporal pattern of the lick activity. Inset, Geometric mean of $q_{\max }$ for all cells in which the information estimate is significantly greater than 0 , and for which temporal coding was present $\left(H_{\max }>H_{\text {count }}\right)$.

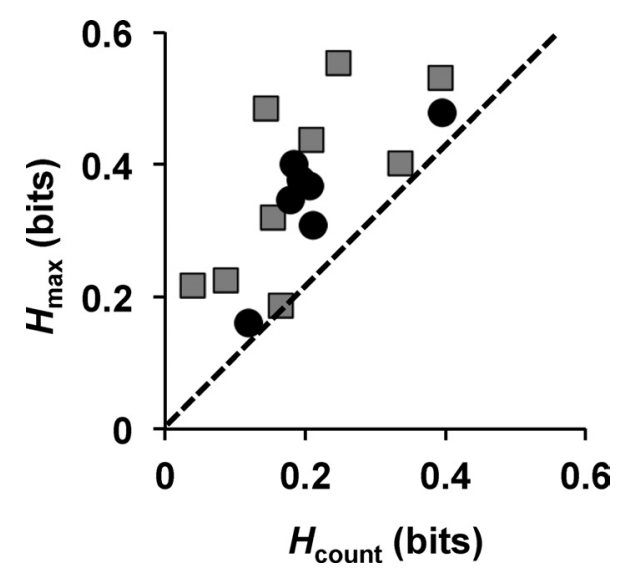

Figure 10. Information (in bits) about taste quality conveyed by spike count $\left(H_{\text {count }}\right)$ versus the maximum information $\left(H_{\max }\right)$. Distance above the dashed diagonal line corresponds to the amount of additional information conveyed by the temporal aspects of the response; for a point on the diagonal line $\left(H_{\text {max }}=H_{\text {count }}\right)$, all information is carried by spike count. The symbol indicates whether the temporal component of the information is accounted for by the firing rate envelope (gray squares, $H_{\max }<H_{\text {exchange }}+2 S D ; n=11$ ), or, alternatively, whether there is an additional contribution from individual spike times (black circles, $H_{\max }>H_{\text {exchange }}+2 S D ; n=7$ ).

about taste quality through the rate envelope of their responses $\left(H_{\max }>H_{\text {shuffled }}+2 \mathrm{SD}\right.$ but $\left.H_{\max } \leq H_{\text {exchange }}+2 \mathrm{SD}\right)$. There were 11 (of $40 ; 28 \%$ ) of these cells. The filled circles indicate those cells for which additional information about taste quality (beyond what is conveyed by the rate envelope) is carried by the timing of individual spikes $\left(H_{\max }>H_{\text {shuffled }}+2 \mathrm{SD}\right.$ and $H_{\max }>$ $H_{\text {exchange }}+2 \mathrm{SD}$ ). There were 7 (of $40 ; 18 \%$ ) of these cells. In sum, approximately one-half ( 18 of 40 ) of the taste-responsive cells conveyed information about taste quality via the temporal aspects of their responses. Of these cells, approximately one-half (11 of 18) carried this information in their temporal envelope; the remainder (7 of 18) carried additional information via individual spike times.

In Figure 11, the amount of information about taste quality in the $120 \mathrm{~ms}$ following each of the stimulus licks was considered separately. The behavior of individual cells is strikingly diverse: some cells primarily carry taste quality information after the first lick, some after the second lick, etc. This generates a spatiotemporal pattern of information across the population of responsive cells. Moreover, most of the cells that carry information about taste quality within individual interlick intervals do so via the temporal characteristics of their spike trains.

\section{Lick and antilick cells}

Many of the recorded neurons had activity that was related to licking activity. One subset of cells showed firing that was timelocked to the licks (i.e., "lick-related cells"); another subset fired only in between licking bouts (antilick cells).

Lick-related activity was encountered in 37 cells of the 107 cell population and was recorded from 11 rats. This included 14 of the $56(25 \%)$ taste-responsive cells, and 23 of the 51 other cells that were not taste responsive but were recorded simultaneously with a taste-responsive cell, either on the same or on a different microwire. (This is an underestimation of the frequency of the latter cell type, since we discarded data from many such cells during our early experiments.)

For cells that were both lick related and taste responsive, the taste responses were superimposed on this rhythmic firing. An example is shown in Figure 12A: this neuron shows excitatory and inhibitory responses to some taste stimuli but also had clear lick-related activity, as evidenced by the evoked responses to dry licks, shown to the right. The cell in Figure $12 \mathrm{~B}$ is an example of a lick-related cell that had no response to any taste stimulus.

In addition to lick-related cells, some of which were taste responsive, we also recorded from 28 NTS cells from 16 rats (in 5 of these, we also recorded taste-responsive cells) that ceased firing when the animal began licking. That is, they fired almost exclusively when the rat was not licking. We refer to these as antilick cells. Interestingly, these cells showed a rapid increase in firing rate just before and just after a lick bout. (A lick bout was defined as a period of at least $1 \mathrm{~s}$ of continuous licking.) Figure $13 \mathrm{~A}$ shows the firing pattern of a typical antilick cell in relation to licking. Figure $13 B$ shows two PSTHs and Figure $13 C$ shows associated raster plots of the firing pattern of the same cell, one centered on the beginning of a lick bout and the other centered on the end of a lick bout. As is apparent from this figure, there is a surge in the firing rate for several seconds, both just before and just after the lick bout. An antilick cell was often recorded in the same session as a taste-responsive cell and sometimes (although rarely) from the same electrode.

\section{Histology}

Of the 29 rats from which taste-responsive cells were recorded, the lesions from 17 were reconstructed. Responses recorded from rats with missing histological data were similar in most respects to responses recorded from rats where electrode locations were reconstructed. Student's $t$ tests were used to compare response latencies and magnitude across stimuli between these groups. Results showed that $\mathrm{NaCl}$ and high sucrose responses had significantly longer latencies (values of $p<0.05$ ) and responses to MSG were larger $(p<0.05)$ in recordings from rats with missing histology. In all other ways, responses were similar in both rats with and without histological data. 
Of the rats in which we did reconstruct the locations of the lesions, Figure 14 shows coronal sections through the NTS in three animals, each containing a lesion associated with a recording site. The numbers in the top left of each panel indicate the distance caudal to bregma. The rat with the lesion shown in Figure 14, top, showed short-latency responses to all taste stimuli tested. In this animal, the recording site was located within the rostral, taste-responsive portion of the NTS. The middle and bottom panels of Figure 14 show the locations of recording sites in animals with taste responses that were of long latency $(>1.0 \mathrm{~s})$. Taste responses recorded from the location shown in Figure 14, middle, showed both short- and long-latency responses. Taste responses recorded from the location shown in Figure 14, bottom, were also both short and long (1.38 s) latencies. These lesions were located $\sim 0.5$ $\mathrm{mm}$ rostral to the point at which the spinal canal opens to become the fourth ventricle. This is also $\sim 0.5 \mathrm{~mm}$ caudal to the most caudal region of the NTS where taste responses are normally recorded in anesthetized rats. This area coincides with the projection field of the vagus nerve (Lundy and Norgren, 2004). There were four rats in which lesions were located caudal to the rostral NTS, all of which showed long-latency taste responses. However, lesions in 11 rats were located in the rostral one-third of the NTS and also showed long-latency responses to taste stimuli. In sum, the histology suggests a rough topographic organization in which cells in the most rostral portion of the NTS contains mostly short-latency taste responses, while cells in the more caudal portions of the NTS, presumably including areas that receive glossopharyngeal and vagal input, respond to taste with both short- and long-latency responses.

\section{Discussion}

Electrophysiological recordings from the NTS of rats as they voluntarily licked revealed that building a neural representation of taste stimuli involves several different cell types. Among these, taste-responsive cells are most numerous. These cells were generally broadly tuned across taste qualities and often showed responses that were time-locked to licks. Taste responses were sometimes not apparent for several licks after the initial stimulus lick, and had latencies that could be as long as 2-3 s. The temporal characteristics of taste responses conveyed significantly more information than spike count alone in almost one-half (45\%) of taste-responsive cells. When tasteevoked activity was analyzed lick-by-lick, a spatiotemporal pattern of activity became apparent, suggesting a reliance on the cooperative activity of many cells to identify taste stimuli. Lick-related cells that showed bursts of activity time-locked to a lick were also recorded in the NTS. Some of these were also taste responsive. Finally, antilick cells that were active only when the animal was not licking were recorded along with

\section{Lick No.}

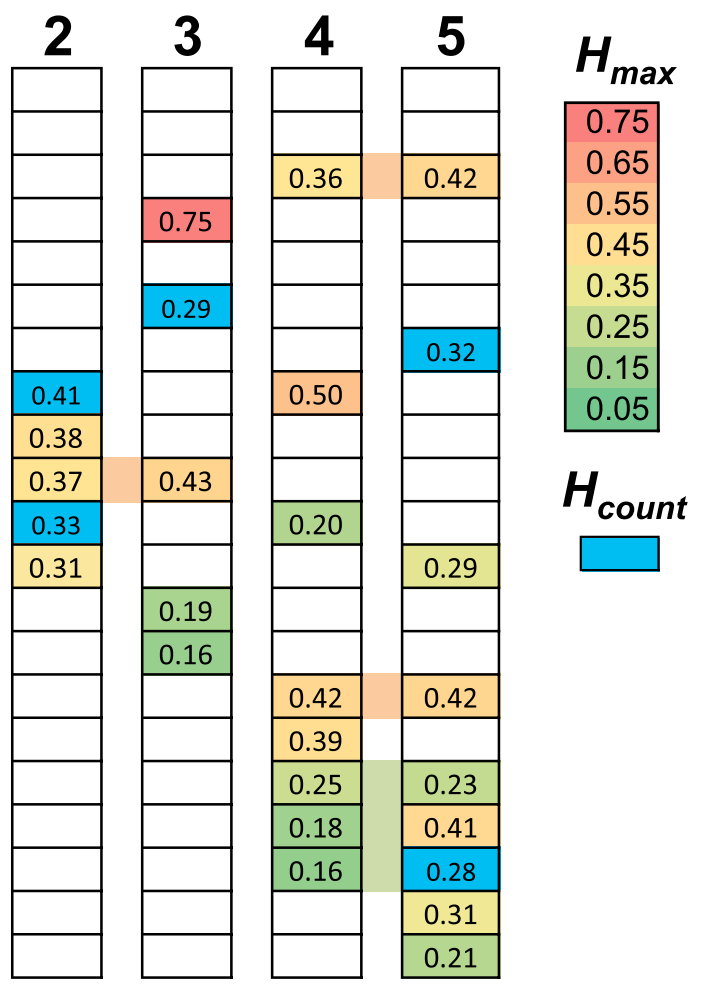

Figure 11. Information conveyed by taste-responsive cells during the $120 \mathrm{~ms}$ following individual stimulus licks. Only cells for (he key at top right; the cells for which this information is carried entirely by count $\left(q_{\max }=0\right)$ are shown as blue. It can be seen that individual cells convey information about taste quality at different .

taste-responsive and lick-related cells. Because these cells are quiescent while the taste-responsive cells are active, their silence corresponds to a "sensory acquisition mode" in the NTS. Collectively, these data underscore the intimate association of active sensory acquisition and its neurophysiological underpinnings.

The sharp contrast between the responses of NTS cells in anesthetized rats receiving passive stimulus delivery and awake rats freely licking a spout is a primary finding of this work. In the first recordings of NTS taste responses in awake rats with passive stimulation, Nakamura and Norgren (1991, 1993) showed that taste cells were generally more narrowly tuned than in anesthetized rats. With active licking, we find that the opposite is true. In addition, the experimental approach of Nakamura and Norgren $(1991,1993)$ precluded the detection of lick-entrained activity, while our data show this type of activity to be widespread. Furthermore, they did not report finding any inhibitory responses, but we found that inhibitory responses were quite common. They also reported that the time course of NTS taste responses was similar to that described in the anesthetized rat (i.e., initial phasic burst followed by a tonic elevation in firing rate). However, most tasteresponsive cells in awake, freely licking rats showed some degree of rhythmic entrainment with the animal's licks.

\section{Long-latency taste responses in the NTS}

The appearance of long-latency ( $\geq 1 \mathrm{~s}$ ) taste responses in the NTS of awake rats has not been previously reported in the NTS 
A
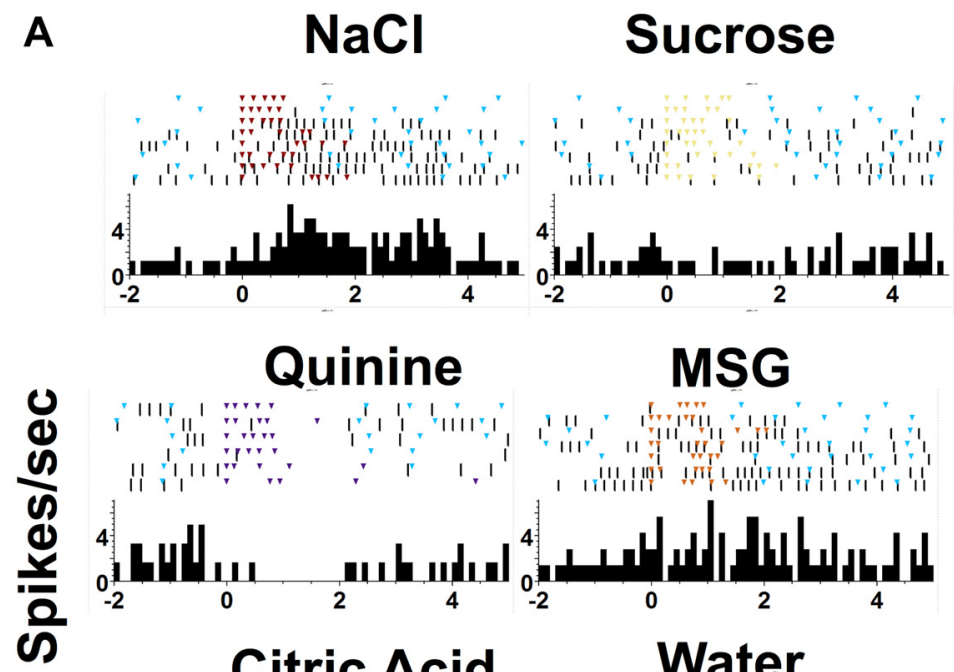

Quinine

MSG

Citric Acid

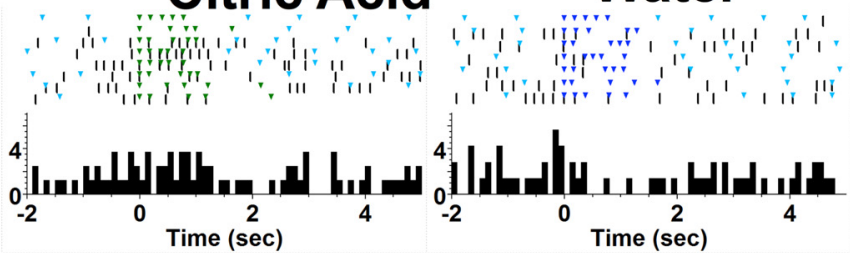

B
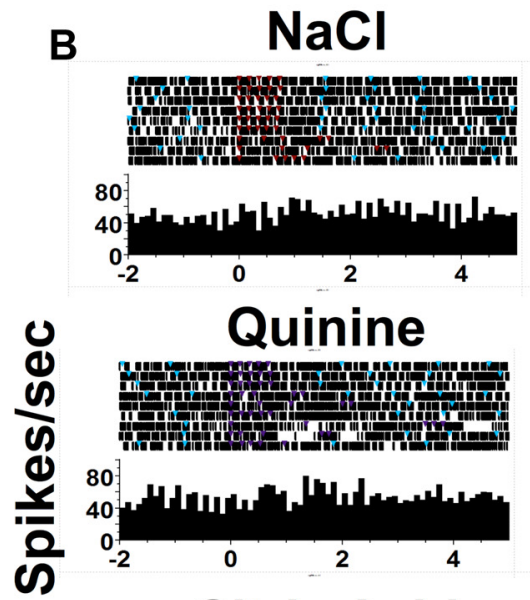

Citric Acid

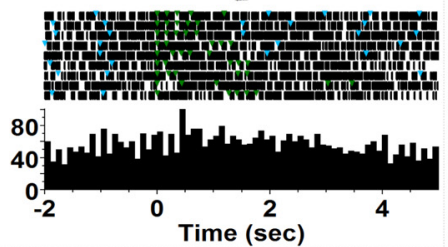

\section{Sucrose}

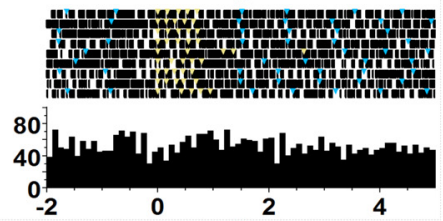

MSG

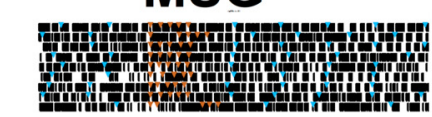

Water
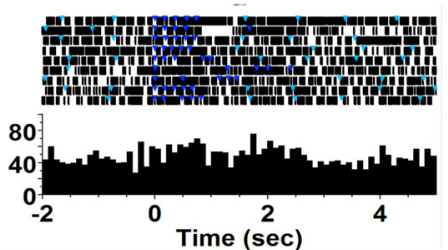

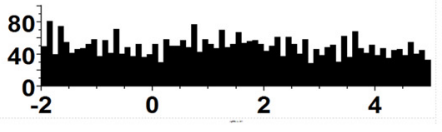

Dry Licks
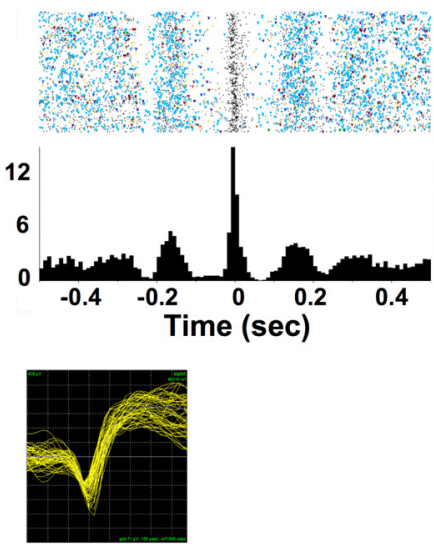

Dry Licks
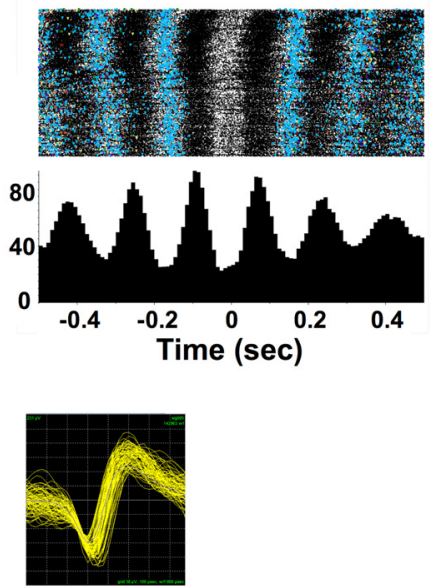

Figure 12. Examples of NTS cells with strong lick-related activity $(n=37)$. Rasters and PSTHs are as in Figure 4. Insets, PSTH triggered by dry licks (top) and the spike waveform (bottom). $A$, A taste-responsive cell (left) with activity that was also time-locked to the dry licks (right). There were 14 cells that showed both taste and lick-related activity. $\boldsymbol{B}, \mathrm{A}$ cell with no response to taste stimuli, but which showed strong lick-related activity. There were 23 cells that showed lick-related activity but did not respond to taste stimuli. For both $\boldsymbol{A}$ and $\boldsymbol{B}$, note the difference in time scales of the taste responses and dry lick PSTH plots: left, time bin, $100 \mathrm{~ms}$; right, time bin, $10 \mathrm{~ms}$.

of anesthetized rats. The latency of these responses is too long for centrifugal input to be a factor. So, what might account for these responses? There are several possibilities. For example, they may be responses to water following some tastants, or be produced by stimulation of taste receptors at the back of the mouth (Geran and Travers, 2006). Alternatively, they may reflect hedonic evaluation of taste stimuli as has been sug- gested in the gustatory cortex (Katz et al., 2001, 2002). Another possibility is that long-latency taste responses may arise from stimulation of extraoral chemoreceptors. By $1 \mathrm{~s}$ after the initial stimulus lick, fluid has almost certainly reached the stomach (Rozengurt and Sternini, 2007), since the average latency for the first swallow during a lick bout is $\sim 1 \mathrm{~s}$ (Travers and Norgren, 1986). From there, information might be re- 
layed to the posterior NTS through the vagus nerve and to the rostral NTS through interneurons (Whitehead et al., 2000). Of note, chemoreceptors for amino acids and bitter substances have been described in the stomach but receptors for sweet stimuli have only been noted in the intestine (Rozengurt and Sternini, 2007). Since we report that all taste stimuli could evoke longlatency taste responses in the NTS, perhaps more than one mechanism is at play.

\section{Temporal coding in the NTS of the awake, freely licking rat}

As in anesthetized rats (Di Lorenzo and Victor, 2003), information about taste quality can be conveyed through temporal coding by NTS cells in the awake, freely licking rat, and in approximately the same proportion of cells. As the response unfolds over time, the maximum amount of information conveyed by temporal coding increases gradually (Fig. 10), as does the proportion of cells that show evidence of temporal coding while the temporal precision decreases over the same interval. These observations imply that, as time passes, the temporal characteristics of the taste-evoked spike train become more informative in more cells. However, the average amount of information in NTS taste responses in awake rats was considerably less than that reported in anesthetized rats [ $60 \%$ of a possible 2.0 bits in the study by Di Lorenzo and Victor (2003) vs $27 \%$ of a possible 2.58 bits in the present study]. There are several factors that may account for this. In addition to the obvious but nontrivial difference in internal state between awake and anesthetized rats (Jones et al., 2006), variability in the physical nature of the stimulus (a small aliquot of fluid with each lick in awake rats vs a long steady flow in anesthetized rats) may have impacted the way that information is processed. In awake rats, individual licks may invite a more intermittent time course for information transfer. Other cells may require the accumulation of information from several licks before they can "decide" on the identity of the stimulus. In addition, descending influences from higher brain areas (Smith and Li, 2000; Cho et al., 2003; Smith et al., 2005; Kang and Lundy, 2010) also likely vary in awake versus anesthetized rats. Since cells in the NTS get input from gustatory, tactile (Ogawa et al., 1988; Halsell et al., 1993), and thermal (Ogawa et al., 1988) afferents as well as share reciprocal connections with forebrain gustatory nuclei (Whitehead et al., 2000; Cho et al., 2003), one can think of them as essentially multimodal. Thus, information about taste quality may represent only a small portion of the information that they may convey about a taste stimulus. Moreover, these data imply that the cooperative activity from ensembles of cells may be necessary for taste quality to be identified. This mechanism has been proposed in the gustatory cortex (Katz et al., 2002; Stapleton et al., 2007; Grossman et al., 2008; Gutierrez et al., 2010).

\section{Lick and antilick cells}

The activity of lick-related cells likely reflects an interplay of gustatory and tactile stimulation (Ogawa et al., 1988; Halsell et al., 1993). Similar lick-related activity has been observed in several neural areas related to gustation (Stapleton et al., 2006; Gutierrez et al., 2010). Although the function of lick-related cellular activity is not known, Gutierrez et al. (2010) have argued that the lick may represent an internal clock (i.e., a reference point for the organization of spike timing). Lick-related input is known to modulate lick pattern in awake rats (Gutierrez et al., 2010), thus coordinating the flow of information into the system at the very earliest stage. Such lick-related bursts in firing in these cells may reflect the essentially rhythmic nature of information that the taste-responsive cells convey about taste quality (Schroeder et al., 2010). In fact, there may be a continuum of cells, with solely lick-related cells at one end and solely tasteresponsive cells at the other, with most cells showing both properties.

The existence of antilick cells among the taste-responsive cells in the NTS raises two questions: the origins of the signals that drive them, and their role in taste perception. While evidence for reciprocal activation of antilick and taste-responsive cells suggests some degree of connectivity, the observation that increases in antilick cell activity precede the cessation of a lick bout suggests that antilick cells are driven by input from more central structures. Krause et al. (2010) have described a subpopulation of cells in the nucleus accumbens, called type 1 cells, that show similar firing characteristics to the antilick cells in the NTS (i.e., they are silent during licking but active 

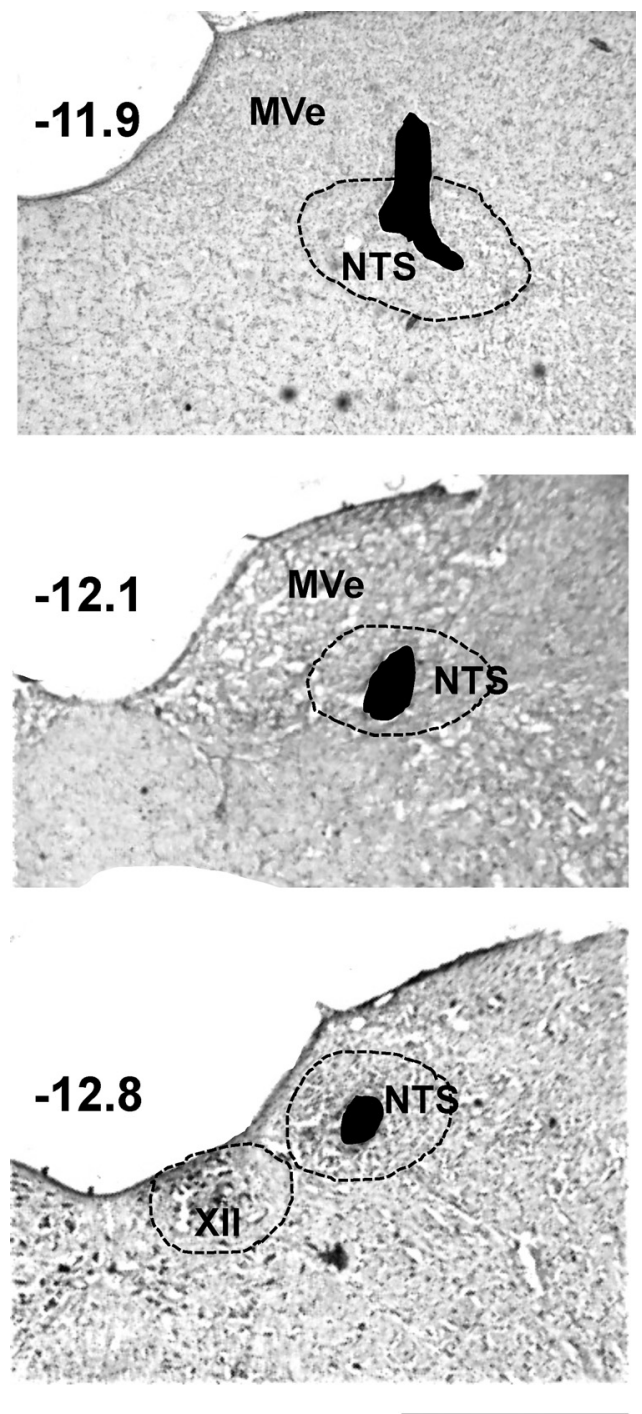

Figure 14. Coronal sections through the NTS showing locations of lesions marking recording sites. Lesions in 17 rats were reconstructed. The numbers in the top left of each panel indicate millimeters posterior to bregma. Scale bar, $1 \mathrm{~mm}$. Abbreviations are as follows: NTS, nucleus of the solitary tract; XII, nucleus of the hypoglossal nerve; MVe, medial vestibular nucleus.

otherwise). Like the antilick cells described here, these cells in the accumbens show a surge just before and just after the lick bout. Krause et al. (2010) proposed that these type 1 cells actively inhibit feeding and suggested that this may occur through an interaction with the lateral hypothalamus. Since the lateral hypothalamus is known to send projections to the NTS (Lundy and Norgren, 2004) and to modulate the activity in taste-responsive neurons in the NTS (Matsuo et al., 1984; Cho et al., 2002, 2003), the lateral hypothalamus may be another source of input that modulates activity in antilick cells. The transition of the antilick cells to quiescence thus marks the onset of a sensory acquisition mode wherein NTS is prepared to actively process taste stimuli as the animal licks. In effect, these cells provide a local representation of the behavioral and sensory mode of the rat. Reciprocal activation of antilick and taste-responsive cells thus provides a way that behaviors that result in acquisition of taste stimuli can be linked to taste processing in the NTS. In all, these data suggest that the ac- tions that result in sensory acquisition may be inextricably linked to the sensory information that is acquired.

\section{References}

Carlton AG (1969) On the bias of information estimates. Psychol Bull 71:108-109.

Chen JY, Victor JD, Di Lorenzo PM (2011) Temporal coding of intensity of $\mathrm{NaCl}$ and $\mathrm{HCl}$ in the nucleus of the solitary tract of the rat. J Neurophysiol 105:697-711.

Cho YK, Li CS, Smith DV (2002) Taste responses of neurons of the hamster solitary nucleus are enhanced by lateral hypothalamic stimulation. J Neurophysiol 87:1981-1992.

Cho YK, Li CS, Smith DV (2003) Descending influences from the lateral hypothalamus and amygdala converge onto medullary taste neurons. Chem Senses 28:155-171.

Cover TM, Thomas JA (1991) Elements of information theory. Wiley series in telecommunications (Schilling DL, ed). New York: Wiley.

Di Lorenzo PM, Victor JD (2003) Taste response variability and temporal coding in the nucleus of the solitary tract of the rat. J Neurophysiol 90:1418-1431.

Di Lorenzo PM, Victor JD (2007) Neural coding mechanisms for flow rate in taste-responsive cells in the nucleus of the solitary tract of the rat. J Neurophysiol 97:1857-1861.

Di Lorenzo PM, Chen JY, Victor JD (2009) Quality time: representation of a multidimensional sensory domain through temporal coding. J Neurosci 29:9227-9238.

Geran LC, Travers SP (2006) Single neurons in the nucleus of the solitary tract respond selectively to bitter taste stimuli. J Neurophysiol 96:2513-2527.

Goldberg DH, Victor JD, Gardner EP, Gardner D (2009) Spike train analysis toolkit: enabling wider application of information-theoretic techniques to neurophysiology. Neuroinformatics 7:165-178.

Grossman SE, Fontanini A, Wieskopf JS, Katz DB (2008) Learning-related plasticity of temporal coding in simultaneously recorded amygdalacortical ensembles. J Neurosci 28:2864-2873.

Gutierrez R, Simon SA, Nicolelis MA (2010) Licking-induced synchrony in the taste-reward circuit improves cue discrimination during learning. J Neurosci 30:287-303.

Halsell CB, Travers JB, Travers SP (1993) Gustatory and tactile stimulation of the posterior tongue activate overlapping but distinctive regions within the nucleus of the solitary tract. Brain Res 632:161-173.

Jones LM, Fontanini A, Katz DB (2006) Gustatory processing: a dynamic systems approach. Curr Opin Neurobiol 16:420-428.

Kang Y, Lundy RF (2010) Amygdalofugal influence on processing of taste information in the nucleus of the solitary tract of the rat. J Neurophysiol 104:726-741.

Katz DB, Simon SA, Nicolelis MA (2001) Dynamic and multimodal responses of gustatory cortical neurons in awake rats. J Neurosci 21:4478-4489.

Katz DB, Simon SA, Nicolelis MA (2002) Taste-specific neuronal ensembles in the gustatory cortex of awake rats. J Neurosci 22:1850-1857.

Krause M, German PW, Taha SA, Fields HL (2010) A pause in nucleus accumbens neuron firing is required to initiate and maintain feeding. J Neurosci 30:4746-4756.

Lundy RF, Norgren R (2004) Gustatory system. In: The rat nervous system, Ed 3 (Paxinos G, ed). San Diego: Academic.

Matsuo R, Shimizu N, Kusano K (1984) Lateral hypothalamic modulation of oral sensory afferent activity in nucleus tractus solitarius neurons of rats. J Neurosci 4:1201-1207.

Miller G (1955) Note on the bias of information estimates. In: Information theory in psychology II-B (Quastler H, ed). Glencoe, IL: Free.

Nakamura K, Norgren R (1991) Gustatory responses of neurons in the nucleus of the solitary tract of behaving rats. J Neurophysiol 66:1232-1248.

Nakamura K, Norgren R (1993) Taste responses of neurons in the nucleus of the solitary tract of awake rats: an extended stimulus array. J Neurophysiol 70:879-891.

Ogawa H, Imoto T, Hayama T (1984) Responsiveness of solitarioparabrachial relay neurons to taste and mechanical stimulation applied to the oral cavity in rats. Exp Brain Res 54:349-358.

Ogawa H, Hayama T, Yamashita Y (1988) Thermal sensitivity of neurons in a rostral part of the rat solitary tract nucleus. Brain Res 454:321-331. 
Roussin AT, Victor JD, Chen JY, Di Lorenzo PM (2008) Variability in responses and temporal coding of tastants of similar quality in the nucleus of the solitary tract of the rat. J Neurophysiol 99:644-655.

Rozengurt E, Sternini C (2007) Taste receptor signaling in the mammalian gut. Curr Opin Pharmacol 7:557-562.

Schroeder CE, Wilson DA, Radman T, Scharfman H, Lakatos P (2010) Dynamics of active sensing and perceptual selection. Curr Opin Neurobiol 20:172-176.

Schweitzer L, Jin Z, Zhang X, Renehan WE (1995) Cell types in the rostral nucleus of the solitary tract. Brain Res Rev 20:185-195.

Smith DV, Li CS (2000) GABA-mediated corticofugal inhibition of tasteresponsive neurons in the nucleus of the solitary tract. Brain Res 858:408-415.

Smith DV, Ye MK, Li CS (2005) Medullary taste responses are modulated by the bed nucleus of the stria terminalis. Chem Senses 30:421-434.

Spector AC, Travers SP (2005) The representation of taste quality in the mammalian nervous system. Behav Cogn Neurosci Rev 4:143-191.
Stapleton JR, Lavine ML, Wolpert RL, Nicolelis MA, Simon SA (2006) Rapid taste responses in the gustatory cortex during licking. J Neurosci 26:4126-4138.

Stapleton JR, Lavine ML, Nicolelis MA, Simon SA (2007) Ensembles of gustatory cortical neurons anticipate and discriminate between tastants in a single lick. Front Neurosci 1:161-174.

Travers JB, Norgren R (1986) Electromyographic analysis of the ingestion and rejection of sapid stimuli in the rat. Behav Neurosci 100:544-555.

Treves A, Panzeri S (1995) The upward bias in measures of information derived from limited data samples. Neural Comput 7:399-407.

Victor JD, Purpura KP (1996) Nature and precision of temporal coding in visual cortex: a metric-space analysis. J Neurophysiol 76:1310-1326.

Victor JD, Purpura KP (1997) Sensory coding in cortical neurons. Recent results and speculations. Ann N Y Acad Sci 835:330-352.

Whitehead MC, Bergula A, Holliday K (2000) Forebrain projections to the rostral nucleus of the solitary tract in the hamster. J Comp Neurol 422 : $429-447$. 